\title{
12 Transdisciplinary learning within tertiary institutions - a space to skin your knees
}

Dena Fam, Abby Mellick Lopes, Cynthia Mitchell

\section{Introduction}

The rise of what Mulgan et al. (2016) term the 'challenge-driven' university has emerged in Australia and internationally as a way of educating students to respond to complex real-world problems. These models of education invite students to respond to complex challenges for which there are no established or single solutions. Instead, students draw on a range of disciplines to solve or improve complex problems; they work in teams; and they collaborate with industry-relevant partners outside of higher education. Collaborative, industry-engaged and interdisciplinary and/or transdisciplinary models of education are well suited to preparing students for the needs of the world (Mulgan 2016), and as such constitute an important complement to traditional models of university education that involve mastering a single discipline. This collaborative, engaged approach to research, teaching, and learning has the potential to complement the controlled, experimental context of a positivist paradigm which tends to limit or reduce the scope of projects and disciplinary perspectives, or subsume disciplinary perspectives to a scientific worldview. In practice, mobilizing disciplinary knowledge in an applied setting necessitates disciplines to coalesce and learn from each other (Mitchell et al. 2016)

While there are many definitions related to the crossing of disciplinary boundaries, Petrie's (1992) review of interdisciplinary education identifies the extent to which integration of knowledge occurs across boundaries. Petrie considers multidisciplinary efforts to be akin to groupwork drawing on different disciplines for the purpose of solving a specific problem, whereas he argues that interdisciplinary approaches seek to integrate different views. Transdisciplinary approaches create a space for multiple, co-existing viewpoints and utilize the discontinuities between views as a source for further inquiry and emergent understanding. These latter approaches also support the systemic collaboration needed to address complex societal challenges (Senge 2006).

The case study presented in this chapter informed the development of a transdisciplinary living lab (Crosby, Fam et al. 2018; Fam, Lopes et al. 2019). This approach to education aims to transcend disciplinary boundaries by utilizing the university campus as a living laboratory in which students engage with a complex problem, in this case the introduction of an alternative sanitation system on campus - a urine diversion system. The Living Lab concept - collaborative learning in a living, social setting - has roots that go back to the experiential, problemfocused approach to learning championed by John Dewey in the early years of the twentieth century (Dewey 1938). His key claim of a continuity between learning and society has underpinned recent developments in living labs, engaged research, 'work integrated learning,' and the development of a research and teaching nexus. These developments attempt to roll back the abstraction of knowledge in academic institutions, and to enhance the contemporary relevance of knowledge in applied contexts. living labs are now commonly understood as collaborative test beds for an innovative approach to problems occurring in a living, social environment where end-users are involved (Daniel 2017, p.2). The Living Lab concept is increasingly being used to explore multi-dimensional and dynamic (or 'wicked') sustainability-related problems in a university setting. A university community has the unique potential to nurture innovation by absorbing risk and valuing the endeavor as a learning experience. The socially and geographically bounded context can help to contain complexity and render it observable. This also introduces an approach to learning where students can "discover[...], examine and fail" in a "safe environment" and where the exchange of knowledge supported by 
living labs taps into the underutilized "brain power" of the entire university, including its stakeholders (Graczyk 2015, p.32).

\section{'Skinning our knees' - trialing innovation in sanitation}

In the context of this case study, "failure" refers to the inability of the sustainable sanitation project to move to the next phase of anticipated wider implementation and scale-up.

As the original proposal stated:

The project has an exploratory intent because we view it as the first tangible step in a long-term program of research and practice. We will pilot urine diversion, recovery and reuse here at UTS with the aim of illuminating the range of interdependent factors that determine successful uptake and potential scale-up of radical sustainable urban sanitation ... Our intention in this project is to open up this very fertile space for further research and practice, and to enable implementation elsewhere, including UTS' new buildings.

The goal of the Sustainable Sanitation Project at the University of Technology Sydney (UTS) was to facilitate the development of urine diversion systems by trialing a system in an urban, multi-story building and investigating what it would take for the system to become viable in an urban environment. The two-year action research project involved the installation of a urine diversion system on campus to collect and treat urine at UTS before processing and reusing the nutrients in urine in agricultural trials at Western Sydney University (then the University of Western Sydney (UWS)). The project is premised on the potential value of urine as a substitute for phosphate rock, the primary component of chemical fertilizers used in agricultural food production. Mined phosphate rock is a rapidly depleting, finite mineral resource that underpins global food security (Cordell, Drangert et al. 2009). At the same time, phosphorus is widely understood as an environmental pollutant which is costly to manage and treat. Ultimately, the project had the aim of developing a proof-of-concept concerning the idea that urine could and should be seen as a resource that could be diverted, captured, transported, and reused in food production and subsequently contribute to closing the phosphorus loop locally (See Chapter 5 by Beal et al. in this book for another perspective on the emergence of UD in Australia). To capture, value, and reuse urine in this way requires a significant transformation in how we think about and manage sewage: viewing it as a resource rather than a waste product. The project presented many technical, institutional, and regulatory challenges in implementing sustainable innovation, as well as social and cultural challenges. These included embedded perceptions of sewage as a waste product, by everyone from toilet users to regulators to agriculturalists.

The project took an action research approach to supporting collaborative learning and to explicitly challenging the cultural fear of failure by acknowledging up-front that we could not know, and indeed did not need to know, everything before we began. The project prepared project partners in two ways: firstly, by making explicit our expectation that we likely would and in fact should plan to 'skin our knees' along the way, and secondly, by making the argument that the university campus was the perfect place for such an experiment. The metaphor, 'skinning our knees' inferred that we would encounter minor incidents from which we could readily recover and keep going, having learned something from the process of falling over. A significant parallel goal of the core research team was to demonstrate the value to industry and academic partners of an emergent approach to research: one where the overarching goal is clear - to trial an innovative, socio-technical system - and where the details of not only the 
design and the methodology, but also the project management milestones, were less clear and needed to be flexible enough to respond to insights revealed along the way.

By taking a transdisciplinary approach, the project engaged with social, technical, cultural, representational, regulatory, and economic issues, in both isolated and integrated ways. Project partners and collaborators included representatives from academia, industry, and government (See Table 12.1 for details). The value and significance of creating a new stakeholder conversation in this project was that it opened a domain of possibility for all stakeholders of 'what could be', creating a surer footing for further experiments and validating learning from failures.

Table 12.1 Collaborators involved in the UTS trial across academia, industry and government

\section{Academia}

Law, agriculture, design, engineering, sustainability, systems thinking

\section{Industry}

Toilet manufacturer, Nursery and Garden Association, water industry

\section{Government}

Department of Health, facilities management, plumbing regulator

Living labs - or the experimental sites for learning-by-doing - are somewhat risky enterprises as they can be resource intensive and often fail to produce the 'disruptive innovation' anticipated by industry stakeholders at the beginning of the process (EU 2015). In the current case study, embracing complexity, the utilization of early generation technology and the unpredictable nature of social participation meant that the project was inherently risky and likely to veer off track. The contained context of the university campus offset some of this risk, since the university could absorb it as research enterprise (Mellick Lopes et al. 2012; Allen et al. 2009). However, while the research presented an acceptable risk for stakeholders invested in innovation and 'discovery learning' (Warburton 2003), the research was more of a challenge for university facilities management and practitioners bound by strict regulations and codes of practice, such as plumbers. Staff responsible for campus operations generally deal with the effective acquisition and use of resources in managing facilities, major projects, and information systems on a daily basis. Our experience mirrored Hoffman and Axson's findings: The project management priorities of operational staff means their view of acceptable risk differs significantly from the views of faculty researchers (Hoffman and Axson 2017). An important dimension of this project therefore was the early involvement of facilities management staff as researchers. This required a collaborative process of framing shared goals, as well as an openness to negotiating tensions that might emerge in the conduct of the research. It was important that the facilities management staff were already committed to sustainability and were invested in improving the sustainability outcomes of campus operations.

In positioning the project as a transdisciplinary initiative, a diverse range of outcomes emerged throughout the project. We have mapped these outcomes against Mitchell et al.'s (2015) Outcome Spaces model which includes: (1) changes in the situation, (2) changes in stocks and flows of knowledge, and (3) mutual and/or transformational learning which occurred for both researchers and research participants (See Figure 12.1 below) 
$<$ Insert Figure 12.1 here $>$

Figure 12.1. Outcomes achieved in the trial of urine diversion systems at UTS

\section{Failure or adaption to changing circumstances?}

While the project was clearly designed to trial the social, technical, and regulatory issues associated with installing innovation in sanitation, unexpected failures and successes emerged and are discussed below.

\section{Project failure to enable scale up}

While the above discussion demonstrates the sustainable sanitation project did achieve a remarkable set of laudable outcomes in just two years (Figure 12.1), it failed at its central goal of enabling scale up by 'opening up the space to further research and practice'. That is, in terms of managing transitions toward more sustainable systems (Loorbach 2010), the project failed to expand the niche systems of sanitation beyond a single experiment, or to influence the broader regime of wastewater management.

The community of practice generated through the project was insufficient to sustain the next phase of research and practice. Each of our project partners either was, or increasingly became, enthusiastic about the need for and potential of urine diversion as a mainstream alternative to conventional sewerage. However, all partners were practitioners - none were in leadership roles, very few were in influential positions within their organizations, and all had the project as an 'extra responsibility' - that is, it was above and beyond their 'real' jobs.

With the benefit of hindsight, it is evident that we failed to invest adequately in building a broader local platform for change that could translate what we did inside the university to an external process (Hansson and Polk 2018). We focused our efforts at two levels. For our niche experiment, we progressed the detail of the research pilot itself, learning what we did not know about UD systems in practice and shattering many myths in the process, creating transformational learning opportunities for ourselves, our project partners, and for our UD research participants. At the broader landscape level, we were involved in media and communications for wide-ranging outlets, as well as publishing journal articles and presenting research findings at industry events. However, we did not engage at the leadership level with key institutions locally. So, even though our project and its outputs embodied relevance, legitimacy, and credibility for internal and external stakeholders, the combination of institutional barriers and lack of seniority contributed to a lack of uptake (Hansson and Polk 2018).

When the project ended, and new sources of funds were sought to continue the work, we had a group of collaborators who could now see and articulate for themselves the value of continuing to explore how to make urine diversion a practical reality, but none of them felt it was their responsibility institutionally to take it forward. When faced with criticism of the idea of urine diversion by others in their fields, our supporters were not confident enough to argue the case. This also relates to the fact that our supporters were not influencers and key decision-makers in their fields. So, whilst they did not shy away from what they had learned, the lack of institutionalization of UD meant that neither did they step forward with their new knowledge to make a different case. 
For example, one way to have scaled up to the next phase of research would have been to implement larger-scale trials of urine as a fertilizer on non-food crops to demonstrate efficacy and explore demand for a more sustainable product. Our nursery industry project participant was entirely supportive of this concept and provided industry contacts for various products so that we as researchers could seek support. However, the socio-cultural taboos associated with using bodily wastes proved too much for these uninitiated industry leads, and every approach by us as researchers was met with a refusal to participate from the horticultural industry. On reflection, this could have been due to the inability to overcome the 'yuck factor' and taboos associated with the use of wastewater in horticulture/agriculture, or it could have been due to the failure of our media communication models to clearly provide justification for niche approaches in the face of embedded centralized norms of wastewater management.

The situation was similar across the project partners. For example, whilst the water utility saw value in the work, and arranged for the outputs to be presented at the general manager level in the organization, there was limited institutional support for further research funding to support the next phase, given a reduction in organizational research funds. The experience gained by the toilet manufacturer made it clear to them that their efforts to develop UD technology should remain focused on urinals, and not expand to toilets. That meant their interest going forward remained on avoiding blockages in pipework. For the local government representative, whilst they had a general commitment to sustainability, their specific issue with managing urine concerned public urination during summer festivals, which they solved in subsequent years by employing transportable urine storage tanks in temporary urinals across the center of Sydney.

As a 'failed innovation,' the sustainable sanitation project proved to be a successful learning exercise on a number of levels. It drew attention to conflicting views about phosphorus that were embedded in the regime of water management - for example, urine was seen as a potential fertilizer but also as a pollutant causing blockages in sewerage pipes. This provided unexpected insights into likely failures occurring behind the scenes in the current system. Pipe blockages due to struvite precipitation are often quoted as a problem for urine diversion activities which is, at a minimum, significant and at times, insurmountable ( $\mathrm{Li}$, Boiarkina et al. 2019). In this project, we revealed that potentially catastrophic struvite build-up was already occurring in conventional urinal piping systems within the University, but it was unknown, undocumented, and therefore unmanaged. The spectacular and slightly gruesome images below speak for themselves (See Figure 12.2).

$<$ Insert Figure 12.2 here $>$

Figure 12.2 Images of documented pipe blockages from struvite build up in piping for conventional urinals.

Within UTS, the combination of an aggressive building program, an institutional commitment to sustainability, and our access to and support from facilities leadership meant that we were able to have an impact. We synthesized the learning from our project, our partners, and international experience into guidance materials for the design and installation of urine diversion pipework and plumbing in multistory buildings. We created the opportunity to make this available to the project managers for a new, \$AUD40m university building being constructed on-campus. As a result, the University requested the contractors install urine diversion plumbing and storage facilities, leading to two 10,000L tanks connected to waterless urinals across ten floors of the new building for a cost of less than $0.1 \%$ of the building. However, the contractors had no experience with urine diversion plumbing. Whilst we had experience, we had limited opportunities to influence them: our relationships were with staff from the 
Facilities Management unit, rather than with the new building project managers directly, so we were given only a limited opportunity to provide advice. The result was that significant errors and omissions occurred during construction of the system, leading to significant operational difficulties and shortcomings. These problems undermined the confidence of facilities management leadership and staff in urine diversion. On reflection, this project required an intervention in the decision-making and procurement process, ideally by providing support for the university in developing specifications for project bidders. In recent years, the existence of the tanks and the ability to collect and store large volumes of urine on campus has enabled a new generation of wastewater treatment research on urine treatment and phosphorus precipitation by colleagues in engineering faculty (see Volpin, Heo et al. 2019).

For most of our academic colleagues, this project was a side-interest. On its completion, most of them returned to their respective disciplinary homes and extant lines of inquiry. Colleagues at Western Sydney University were the exception - they went on to conduct further small-scale research on the application of urine as a fertilizer, and to further explore design's contribution to transdisciplinary research (see Mellick Lopes et al. 2012). This group, in collaboration with a subset of the original group, has moved further into the development of experimental learning models with an emphasis on transdisciplinarity, and has collaboratively developed a model of transdisciplinary education for teaching and learning (Crosby, Fam et al. 2018; Fam, Mellick Lopes et al. 2019).

All of this meant that transdisciplinary research on urine diversion systems was not adequately planned for, and thus fell between the cracks in terms of resourcing. The Australian Research Council remained focused on disciplinary research, industry research funds were focused on applications that were closer to implementation, and no partner felt sufficient responsibility for the topic to step into a leadership role. In other words, our assumption that the experience of the project and the knowledge and practice discoveries revealed by the project would be sufficient as a platform to move forwards was not well founded.

There was a second confounding factor on top of this lack of an obvious source for the next phase of funding, and that was the business model of the institute that housed the lead investigators. It operates on a self-funding arrangement, which means the researchers must bring in funded research projects. Investment in new business development is possible, but only to a degree. By the time it became apparent that we had underestimated the need to invest during the project itself in building a coalition of partners who would back further investment, two competing pressures combined to stop further work. Firstly, the level of effort required to seek alternative funds was becoming too high, and secondly, the PI's success in winning research projects in other areas meant there was no capacity to continue a significant involvement in UD research. In short, projects that undertake ambitious tasks of facilitating system change of embedded infrastructures require long-term support encompassing financial, human, and institutional resources.

\section{Engaging a diversity of knowledge regimes}

Limited research and knowledge on early generation urine diversion systems (Fam, Mitchell et al. 2009) at the time of the pilot project revealed the importance of considering not only the technological system but also the contextual nature of technological 'solutions'. The pilot revealed that it is not only a matter of installing the 'right' technology but importantly the technology needs to be situated and socialized by those using, cleaning, and maintaining the system if it is to be successful over the long term (Lopes, Fam et al. 2012). 
Operational knowledge, including the practical insights provided by cleaners, plumbers, and facilities staff, emerged as a critical form of knowledge in relation to identifying problems in practice that were important to resolve to ensure the ongoing viability of the new system being piloted. While, for example, the plumber was an enthusiastic participant in the research, it was not easy for him to go against years of compliance with the Plumbing Code in adapting plumbing pipework to accommodate the urine diversion toilets and system. While the code requires an odor trap to be installed with all sanitary fixtures, the researchers had hypothesized that in order for the urine to drain effectively, the S-bend odor trap needed to be removed. As Mitchell et al. (2013, p. 25) state "[the plumber's] first response was to enlarge the trap, and then to simplify the trap, and finally, to assuage our relentless requests, to remove the trap altogether." The impacts of the new system on plumbing practices required a critical analysis of current codes to determine points of flexibility and support for practitioners, including briefs for communications about installation practices and pipe gradations.

While no toilet design 'survived' the trial as a radical innovation intact, these deliberations had a positive impact that made inroads into the plumbing community, and led to the framing of a new professional identity: the 'yellow plumber' (Kyriakou 2010). Mitchell et al. (2013, p. 25) write: "this experience highlighted that even the best plumbers need training to appreciate and apply the distinctive principles for urine pipework when they depart from conventional plumbing codes". This example illustrates the necessity of involving a diversity of knowledge regimes in transdisciplinary experiments as it expands the project 'field of vision', particularly as it pertains to innovation in the critical areas of adaptation and retrofitting. See Figure 12.3 below for the layout of the urine diversion toilet and sampling system installed.

$<$ Insert Figure 12.3 here $>$

Figure 12.3. Illustration of UD toilet and sampling system (Mitchell et al. 2013)

\section{Clarifying roles and expectations of team members in transdisciplinary projects}

The current model of tertiary education tends to focus on knowledge creation emerging from current disciplinary paradigms rather than transformational learning (Schön 1987). Academic partners in the project were influenced by the 'politics of research' (Altman 1995) and the need to publish research through peer reviewed publications to fulfil expectations of their academic institutions. The expectation that academic members would produce research outputs had not been clearly articulated in the early stages of the project but was clarified as the project progressed. When it became apparent that academic members were, in many cases, disinclined to participate due to lack of institutional support, the facilitating team renegotiated incentives for academics to meet institutional requirements, for example by offering financial incentives, opportunities for research outputs and research assistance. Evidence from the project suggests that articulating both individuals and institutional expectations helps identify potential barriers to the sustained engagement of academic members (Fam 2017).

Working in transdisciplinary teams requires adopting a posture of collaboration which requires openness, a willingness to share knowledge and expertise outside disciplinary silos, and to accept that intellectual property and project results are being shared and collectively owned. It also means a willingness to encounter the limits of one's own knowledge and expertise which could be another example of 'skinning the knees'. Collaboration and an open approach to research discovery is novel for many academic researchers more familiar with working in disciplinary silos, building disciplinary expertise, and seeking individual recognition and reward for their input. 
While cross-disciplinary collaboration and decision-making was perceived by the facilitating team as necessary for trialing innovation, it was not universally accepted by all community members as a legitimate form of research collaboration. For example, one member viewed participatory input into decision-making as unnecessary and unprofessional, suggesting that, 'being participatory to arrive at an outcome may sound democratic but ends in compromise ... that serves no-one. It's also an abdication of professionalism which is totally unnecessary' (Academic team member). While cross-disciplinary decision-making was widely accepted in theory, it was not until implementing participatory decision-making processes in practice during the design phase of the project that issues arose with certain team members perceiving disciplinary expertise to be compromized by participatory processes (Fam 2017).

\section{Learning through failure and unexpected successes along the way}

An unexpected outcome was the role of visual communication design in transdisciplinary research and collaboration. Visual communication in research often plays a representational role, entering the field after 'knowledge creation' to produce information graphics or diagrams to support the translation and dissemination of the research in the public domain. However, in this project, visual communication was brought in at an early stage to facilitate social engagement for the duration of the research. This was a direct result of an identified absence of the end-user voice in previous 'top-down' UD experiments (Fam and Mitchell 2013), leading to critical questions about the engagement of everyday social actors in facilitating system change (Mellick Lopes et al. 2012). Part of the impetus of involving visual communication was the prevalence of poor visual assets in previous pilots. In the early stages of this project, it became clear that user manuals, signage and other artifacts would help facilitate new social practices of plumbers, cleaners, and everyday toilet users, and would be a significant element of the investigation, demarcating and providing indices for a new territory of practice. It was also deemed important to involve visual communication in promoting system literacy to engage the university community and the broader public in the 'story' of the project. At the start of the project, it was assumed that visual artifacts produced by two student groups involved in the project would be exhibited. However, what eventuated was a much more open-ended set of tools, including an in situ graffiti board that became a key instrument of social data collection over the eight months of the trial, capturing frank, practical, and creative inputs of everyday users (See Figure 12.4) and that visual communication design could provide insight into the range of collaborative input across strands of research (see Figure 12.5).

$<$ Insert Figure 12.4 here $>$

Figure 12.4. Graffiti board in situ and detail: used to collect end-users' feedback on the system, Designer: Yana Mokmargana (WSU)

<insert figure 12.5 here $>$

Figure 12.5 Development of a visual communication strategy building collaborative input across strands of research (Mellick Lopes et al. 2012)

\section{The importance of social learning}

The transdisciplinary approach adopted in the project highlighted the importance of creating space for social interaction and social learning. Originating from concepts of organizational 
learning (Argyris and Schön 1978, 1996; Senge 1990; Wenger 1998), social learning has at its core a sense of the importance of the co-generation of knowledge. In the example of the graffiti board, participants noticed that the project team was taking action in response to comments. Said one participant, 'It seems comments are taken seriously and results in new little tweaks!' 'Tweaking' the system to align with user needs and expectations demonstrated the co-generation of knowledge and the truly socio-technical nature of the experiment (Fam and Lopes 2015). Rather than truth-seeking instruments, the social research tools used in this project were much more like 'minor tools of situated demand management' to draw on an idea from Sofoulis (2005). This approach enabled the project to model an everyday politics of transitions (how to do transitions in practice) and highlighted the significance of situated, applied and operational knowledge in system change.

Social learning was highlighted by team members as an important characteristic of the project. Team meetings were deliberately structured to support conversation between cross-disciplinary members and the relationship between them and, in the process, to develop collective problem definitions and identification of potential solutions. Most team members interviewed as part of the project wrap-up (9 of the 11 members) noted that conversation between members was a significant learning experience, with one team member reflecting that, 'The social dimension of the project has been a very important instigator of my learning. It's not me going off and reading something on my own necessarily. It's that plus the conversation... plus, the interactive experience' (Academic team member). The academic investigators forming part of the wider research team were also conscious that didactic, autonomous, disciplinebased courses rarely seek to foster an advanced social networking culture among students - a culture which is commonly credited with promoting deep learning (Gray, Williams et al. 2014)

As the experiment broached new territory, new productive relationships amongst stakeholders were also charted, with an unforeseen mode of interaction emerging in the form of collaborative writing as a process of learning. The importance of collaborative writing, not only as a research contribution and academic output, but also as a mode of learning, had not been recognized in the early stages of the project. Over the two years of the project, academic conference/journal publications were written across the fields of systems thinking, design education and transition management, design studies, and transdisciplinary collaboration involving both industry and academic contributors. The social nature of academic writing with crossdisciplinary partners could be defined within the UTS project as a particular mode of social learning (Fam 2017). One industry partner highlighting that, 'in working with purely agricultural scientists ... [writing together in the project] stretched my imagination a bit and made me think a little bit differently in how we approach the issue [of trialing a new system]' (Industry partner). The opportunity to utilise academic writing as an interdisciplinary mode of learning was enhanced by the fact that half of the members of the community were academics, each with a distinct and unique disciplinary background.

\section{Learning to run a transdisciplinary project while incorporating a research-teaching nexus}

The UTS project was an opportunity for the authors to design an educational program for undergraduate students closely linked to an industry-funded project aimed at transitioning to an alternative sanitation system. One of the key outcomes for the project team was learning how to run a transdisciplinary project with a diverse range of partners while at the same time involving students as participant researchers. The challenges to disciplinary knowledge experienced by researchers were also experienced by students, as the project demanded an organic, adaptive approach to learning not often encountered in traditional disciplinary training. The 
project created novel spaces for creative student engagement, which promoted deep learning and sophisticated intellectual interactions in the sustainability sphere (Gray et al. 2014). What emerged as a result of this project was the development of a model for transdisciplinary education, in particular the evolution of the 'Transdisciplinary Living Lab Model' (TDLL) (Fam, Lopes et al. 2019) with a research-teaching nexus at its core. Building on the collaborative and applied learning context of the sanitation project, which had a high degree of affinity with design as an interventionist and future-oriented discipline, the TDLL seeks collaboration with industry, government and university operational staff to provide transdisciplinary learning opportunities for students in relation to campus-focused sustainability research. The TDLL provides an opportunity for students to engage with the Sustainable Development Goals (SDGs) and the concept of planetary boundaries (or the safe operating space for humanity based on the biophysical processes regulating earth systems) while designing system interventions in fulfilment of their course requirements. The decision to incorporate the SDGs and the concept of planetary boundaries into the TDLL model was made to encourage students to critically reflect on the impact of their solutions to complex problems on global systems.

The TDLL is problem-focused and action-oriented, and deploys participatory approaches to support collaborative transdisciplinary input into improving complex problems such as waste and water management. The development of the TDLL was unapologetically 'interventionist' in the way it framed, structured, and organized the discourse about the problem being addressed. That is, the research-teaching nexus took an interventionist approach to ask 'what could be' (Brown 2010), with the view that system change is not simply technical, but also social and cultural, with material infrastructural and immaterial symbolic dimensions. The student/researchers are therefore required to develop a rich understanding of the sustainability problem being investigated, starting with their own everyday practices, and they are required to identify a point of intervention from inside the system. Utilising the campus as a living laboratory provides the context for students to engage with waste and sanitation systems daily, and to further investigate both the visible and commonly invisible components of the system including technologies, actors (cleaners, facilities personnel), and practices (Fam et al. 2019).

In the higher education context, on-campus living labs are one way to create an environment that supports transdisciplinary research, bringing members of the public, business, government, and researchers together to co-create services, systems, technologies, and societal solutions. Linking curriculum, operations, and research via the mechanism of a living lab offers a holistic and systemic way to support the university and its researchers, students, and graduates to practically meet sustainability goals.

\section{Discussion: How should tertiary institutions support learning through failure in transdisci- plinary projects?}

Universities need to change from functioning primarily as service providers to the (current) labor market, which inherently diminishes a future-focused perspective, to taking more of a cultural leadership role and deliberately facilitating cultural change. This project was less about 'work integrated learning' than about facilitating a grander social learning project that needs to be undertaken by the culture at large if we are to transition to more sustainable futures. 
In this respect, the industry and government partners in the project were partners in discovery learning, rather than clients seeking the university's services to problem solve. As sustainable designer Ezio Manzini writes:

The transition toward sustainability is a massive social learning process. The radical nature of the objective (learning to live better while leaving a light ecological footprint) requires vast experimentation, a vast capacity for listening and an immense degree of flexibility in order to change... Sustainability and the conservation and regeneration of environmental and social capital means breaking with the currently dominant models of living, production, and consumption, and experimenting with new ones. A social learning process on this vast scale must involve everybody (2008, p.16).

This is becoming all the more urgent, as indicated by the 2018 Intergovernmental Panel on Climate Change (IPCC) report which notes that, "Limiting global warming to 1.5 degrees $\mathrm{C}$ would require rapid, far reaching and unprecedented changes in all aspects of society" (IPCC 2018), including in how we manage our waste, water and energy services. All of these services have the potential to be explored on-campus as part of a research-teaching nexus, which deliberately places students inside a complex living sociotechnical system.

Importantly, the project enabled the space, not only for social learning amongst project partners, but also for exploring future possibilities and the 'unknowns' associated with UD systems. An important characteristic of transdisciplinary research is, of course, creating the space to explore the 'unknowns' and emergent issues/matters of concern as they arise (Bammer 2013). A number of unexpected lessons were learned throughout the project. For example, the core project team would not have theorized the agency of visual communication in transdisciplinary projects so usefully if not for the opportunity for this practice-oriented discipline to participate in, rather than merely provide services to, the research. This enabled questions about the role of disciplinary knowledge and expertise in transdisciplinary project teams to emerge (Mellick Lopes et al. 2012).

Unexpected knowledge was also gained by working closely with key operational staff such as builders, plumbers, and cleaning staff who managed the everyday maintenance of the UD toilets. What became increasingly apparent from feedback from cleaning staff in particular was the importance of catering to a culturally diverse community and the culturally specific toilet practices they observed. With a significant proportion of UTS students coming from Asian and South East Asian backgrounds, a preference for using squatting rather than seated toilets was identified by cleaners. Cleaners had highlighted to the team that approximately 20 toilets were broken per week from students squatting on toilet seats. This involved a cost of approximately $\$ 150,000 /$ year as well as significant risk of harm to the user if the porcelain toilet shattered in the process. This cost could be significantly reduced by installing culturally acceptable squatting toilets to cater for differing toilet practices amongst students. While this project was not focused on identifying diverse toilet practices, the need for culturally diverse input into future research is needed, reflecting the increasing cultural diversity of the Australian population. Approximately half of the current Australian population consists of either people born overseas or people with one or more parent born overseas (Australian Bureau of Statistics 2016). UTS reflects national statistics with approximately $50 \%$ of current students born overseas in (UTS 2018).

The project led to the installation of pipework in large new development in urban Sydney an example of how this project did lead to a 'scaling up' of sorts, if not of the kind envisioned 
at the beginning of this project - and to new lines of research in agriculture and law on the reuse of waste streams as fertilizer products. It also led to insights about new professional identities, such as the 'yellow plumber'. And importantly, it exposed the provisional and contingent nature of promising technologies and the need for significant research investment to negotiate the tension between what has worked in the past and exploration of new fields of knowledge (Gherardi 2012).

\section{Conclusion}

One challenge encountered in conducting transdisciplinary courses and subjects within university programs is that generalizability is actively sought, yet under current models, frameworks, and approaches it is not always possible to transfer 'lessons learned' to other transdisciplinary projects which may cross sectors, disciplines, and views of what constitutes valid knowledge and research. What this project provided was the space to 'skin our knees' together, and productively learn from the experience. However, the capacity to sustain the learning engendered by the project was hampered by the failure to invest adequately in building a broader local platform for change from project inception, which could translate what we did inside the university to an ongoing, external process. In hindsight, this is particularly important for a project so far ahead of the current status of the complex system of sanitation, including its social, cultural, and material elements. In addition, if transdisciplinary research exploring the potential of innovative infrastructural solutions is to be valued, funding bodies need to recognize the need for longitudinal research and collaborative participatory approaches, and the difficulty in determining the finish line of experimental projects.

\section{Take-home messages:}

- Provide a space where those involved in transdisciplinary projects can 'skin their knees' so that both project partners and students are primed to value challenges and failures as a key opportunities for learning. Create an understanding among collaborators that they are likely to 'skin their knees.'

- When considering project legacy, build a broader local platform for change from the very inception of the project to ensure project findings have impacts beyond the boundaries and limited timeframe of the project.

- In experimenting with innovative infrastructural solutions radically different from the mainstream (particularly in sanitation systems), ensure that social, cultural, and material elements are all considered in the process of transdisciplinary inquiry.

\section{References}

Allen, J., et al. (2009). Futures west: a design research initiative promoting sustainable futures for western sydney. Proceedings of the Cumulus Conference: $38^{\circ}$ South: hemispheric shifts across learning, teaching and research, Melbourne .

Altman, D. G. (1995). Sustaining interventions in community systems: On the relationship between researchers and communities. Health Psychology 14: 526-536.

Australian Bureau of Statistics (2016). Census of population and housing.

Bammer, G. (2013). Disciplining interdisciplinarity: integration and implementation sciences for researching complex real-world problems. Canberra: Austrailan National University E-Press.

Cordell, D., et al. (2009). The story of phosphorus: global food security and food for thought. Global Environmental Change Journal 19: 292-304.

Crosby, A., et al. (2018). Trandisciplinarity and the 'living lab model': food waste management as a site for collaborative learning. In F. D, N. L and P. Gibbs. 
Transdisciplinary theory, practice and education: The art of collaborative research and collective learning. London: Springer.

Daniel, A. (2017). Strategic opportunities for sustainability-focused living laboratories at Western Sydney University. Western Sydney University. December, 2017

Dewey, J. (1938). Experience and education. New York: Collier.

EU (2015). Practical guidelines for establishing and running a city logistics living lab, http://www.citylab-project.eu/deliverables/D3_1.pdf Accessed January 20th, 2020

Fam, D. (2017). Facilitating communities of practice as social learning systems: a case study of trialling sustainable sanitation at the University of Technology Sydney (UTS). Knowledge Management, Research and Practice 15(3): 391-399.

Fam, D. and Lopes, A. M. (2015). Designing for system change: innovation, practice and everyday water. Acme 14(3): 735-750.

Fam, D., et al. (2019). The transdisciplinary living lab model (TDLL). In W. L. Filho, A. L. Salvia, R. Pretorius et al. Universities as living labs for sustainable development supporting the implementation of the Sustainable_Development Goals. London: Springer.

Fam, D. and Mitchell, C. (2013). Sustainable innovation in wastewater management: lessons for nutrient recovery and reuse. Local Environment 18(7): 769-780.

Fam, D., et al. (2009). From removal to recovery: critical stakeholder involvement in implementing pilot projects of urine diversion systems in Sweden. The first annual Asia-Pacific Science Technology and Society Conference - Our Land, Our Waters, Our People. Griffith University, Brisbane, Australia.

Geels, F. (2002). Technological transitions as evolutionary reconfiguration processes: a multi-level perspective and a case study. Research Policy 31(8-9): 1257 - 1274.

Gherardi, S. (2012). Why do practices change and why do they persist? Models of explanations. In P. Hager, A. Lee and A. Reich.Practice, learning and change: practice-theory perspectives on professional learning. Dordrecht, Germany: Springer Verlag.

Graczyk, G. (2015). Masters Thesis - Embedding a living lab approach at the University of Edinburgh The University of Edinburgh.

https://www.ed.ac.uk/files/atoms/files/embedding_a_living_lab_approach_at the_un iversity_of_edinburgh.pdf, Accessed, January $20^{\text {th }}, 2020$.

Gray, J., et al. (2014). Lessons learnt from educating university students through a transdisciplinary project for sustainable sanitation using a systems approach and problem-based learning. Systems 2: 243 - 272.

Hoffman, A. and Axson, J. (2017). Examining interdisciplinary sustainability institutes at major research universities: innovations in cross-campus and cross-disciplinary models. Ann Arbor, MI: Cynthia and George Mitchell Foundation.

IPCC (2018). Global warming of $1.5^{\circ} \mathrm{C}$. An IPCC special report on the impacts of global warming of $1.5^{\circ} \mathrm{C}$ above pre-industrial levels and related global greenhouse gas emission pathways, in the context of strengthening the global response to the threat of climate change, sustainable development, and efforts to eradicate poverty V. Masson-Delmotte, P. Zhai, H. O. Pörtner et al.

Kyriakou, D. (2010). The yellow plumber. Plumbing Connection. https://plumbingconnection.com.au/yellow-plumber/

Li, B., et al. (2019). Phosphorous recovery through struvite crystallization: Challenges for future design. Science of the Total Enviromnment 648: 1244-1256.

Lopes, A., et al. (2012). Designing sustainable sanitation: involving design in innovative, transdisciplinary research. Design Studies 33(3): 298-317. 
Manzini, E. (2008). Design context: enabling solutions for sustainable urban everyday life. In E. Manzini, S. Walker and B. Wylant. Enabling solutions for sustainable living: a workshop. Calgary, Canada: University of Calgary Press.

Mitchell, C., et al. (2015). Beginning at the end: the outcome spaces framework to guide purposive transdisciplinary research. Futures 65: 86-96.

Mulgan, G., et al. (2016). The challenge-driven university: how real-life problems can fuel learning. NESTA. https://www.nesta.org.uk/blog/the-challenge-driven-universityhow-real-life-problems-can-fuel-learning/

Petrie, H. G. (1992). Interdisciplinarity Education: Are We Face with Insurmountable Opportunities? Review of Research in Education(18).

Schön, D. A. (1987). Educating the reflective practitioner: toward a new design of teaching and learning in the professions. San Francisco: Jossey-Bass Publishers.

Senge, P. M. (2006). The fifth discipline: the art and practice of the learning organization London: Currency Doubleday.

Sofoulis, Z. (2005). Big water, Everyday water: A sociotechnical perspective. Journal of Media and Cultural Studies 19(4): 445-463.

Thompson-Klein, J. (2004). Prospects for transdisciplinarity. Futures 36(4): 515-526.

UTS (2018). Facts, figures and rankings. from https://www.uts.edu.au/about/university/factsfigures-and-rankings.

Volpin, F., et al. (2019). Techno-economic feasibility of recovering phosphorus, nitrogen and water from dilute human urine via forward osmosis. Water Research 150: 47-55.

Warburton, K. (2003). Deep learning and education for sustainability. Interna-

tional. Journal of Sustainability in Higher Education 4(1): 44-56. 